\title{
Influence of the Antarctic ozone hole on the polar mesopause region as simulated by the Canadian Middle Atmosphere Model
}

Article

Accepted Version

Lossow, S., McLandress, C. and Shepherd, T. G. (2012) Influence of the Antarctic ozone hole on the polar mesopause region as simulated by the Canadian Middle Atmosphere Model. Journal of Atmospheric and Solar-Terrestrial Physics, 74. pp. 111-123. ISSN 1364-6826 doi: https://doi.org/10.1016/j.jastp.2011.10.010 Available at https://centaur.reading.ac.uk/31548/

It is advisable to refer to the publisher's version if you intend to cite from the work. See Guidance on citing.

To link to this article DOI: http://dx.doi.org/10.1016/j.jastp.2011.10.010

Publisher: Pergamon

All outputs in CentAUR are protected by Intellectual Property Rights law, including copyright law. Copyright and IPR is retained by the creators or other copyright holders. Terms and conditions for use of this material are defined in the End User Agreement. 


\section{www.reading.ac.uk/centaur}

\section{CentAUR}

Central Archive at the University of Reading

Reading's research outputs online 


\title{
Influence of the Antarctic ozone hole on the polar mesopause region as simulated by the Canadian Middle Atmosphere Model
}

\author{
Stefan Lossow ${ }^{\mathrm{a}, \mathrm{c}, \mathrm{d}}$, Charles McLandress ${ }^{\mathrm{b}}$, Andreas I. Jonsson ${ }^{\mathrm{b}}$, Theodore G. \\ Shepherd ${ }^{\mathrm{b}}$ \\ ${ }^{a}$ Chalmers University of Technology, Department of Earth and Space Sciences, \\ Hörsalsvägen 11, 41296 Göteborg, Sweden. \\ ${ }^{b}$ University of Toronto, Physics Department, 60 St. George Street, Toronto M5S 1A7, \\ Canada. \\ ${ }^{c}$ now at Karlsruhe Institute of Technology, Institute for Meteorology and Climate \\ Research, Hermann-von-Helmholtz-Platz 1, 76344 Leopoldshafen, Germany. \\ ${ }^{d}$ formerly at Stockholm University, Department of Meteorology, Svante-Arrhenius-väg \\ 16c, 10691 Stockholm, Sweden.
}

\begin{abstract}
It is well established that variations in polar stratospheric winds can affect mesospheric temperatures through changes in the filtering of gravity wave fluxes, which drive a residual circulation in the mesosphere. The Canadian Middle Atmosphere Model (CMAM) is used to examine this vertical coupling mechanism in the context of the mesospheric response to the Antarctic ozone hole. It is found that the response differs significantly between late spring and early summer, because of a changing balance between the competing effects of parametrised gravity wave drag (GWD) and changes in resolved wave drag local to the mesosphere. In late spring, the strengthened stratospheric westerlies arising from the ozone hole lead to reduced eastward GWD in the mesosphere and a warming of the polar mesosphere, just as in the well
\end{abstract}

Email address: stefan.lossow@kit.edu (Stefan Lossow) 
known mesospheric response to sudden stratospheric warmings, but with an opposite sign. In early summer, with easterly flow prevailing over most of the polar stratosphere, the strengthened easterly wind shear within the mesosphere arising from the westward GWD anomaly induces a positive resolved wave drag anomaly through baroclinic instability. The polar cooling induced by this process completely dominates the upper mesospheric response to the ozone hole in early summer. Consequences for the past and future evolution of noctilucent clouds are discussed.

Keywords: ozone hole, mesopause region, vertical coupling, NLCs 


\section{Introduction}

2 Increasing concentrations of greenhouse gases (GHGs), in particular $\mathrm{CO}_{2}$, 3 cool the middle atmosphere. This climate change signal, which peaks around 4 the stratopause, is expected to result in cooling through this century as GHG 5 concentrations continue to increase. While a clear cooling signal has already 6 been identified in the upper stratosphere which is considerably in excess of 7 that attributable to ozone depletion (e.g. Ramaswamy et al., 2001; Randel 8 et al., 2009), and there is some evidence for strong cooling in the lower and 9 middle mesosphere (Beig et al., 2003), no significant temperature trends have 10 yet been observed in the mesopause region (Beig et al., 2003). This is in part 11 due to the expected weaker $\mathrm{CO}_{2}$ cooling and the comparatively large level of 12 natural variability at these heights, which makes detection of a statistically 13 significant trend difficult. In addition, there is a lack of sufficiently long14 term temperature datasets to identify trends, resulting in trend estimate 15 uncertainties of about $2 \mathrm{~K} /$ decade (Beig et al., 2003).

${ }_{16}$ It has been argued, however, that the impact of climate change on the 17 mesopause region may be indirectly estimated from observations of noctilu18 cent clouds (NLCs) (Thomas et al., 1989; von Zahn, 2003; Thomas et al., 19 2003). NLCs form at the cold summer mesopause where temperatures typi20 cally fall below $130 \mathrm{~K}$ (Witt et al., 1964), and have been observed for decades 21 at high northern latitudes. These low temperatures allow the formation of ice 22 particles which typically occur from $\sim 25$ days before to 60 days after summer 23 solstice. The particles nucleate around the mesopause $(\sim 88 \mathrm{~km})$, consume 24 the ambient water vapour, grow, and sediment. Below about $82 \mathrm{~km}$ the ice 25 particles encounter warmer temperatures and quickly sublimate. When these 
26 ice particles exceed sizes of $30 \mathrm{~nm}$ they become optically visible. Since NLCs

${ }_{27}$ exist in extreme conditions they are very sensitive to changes of the ambient

28 water vapour and especially temperature (Rapp and Thomas, 2006). Thus,

29 as concentrations of $\mathrm{CO}_{2}$ and methane (the main source of water vapour in

so the middle atmosphere) increase, so too should the frequency of occurrence 31 of NLCs.

32 Indeed, observations show that NLC occurrence rate, brightness, season

33 length and latitudinal extent have all increased during the last decades (e.g.

34 Klostermeyer, 2002; DeLand et al., 2007; Gadsden, 2002; Wickwar et al., 35 2002). However, the lack of corresponding temperature and water vapour 36 measurements makes it difficult to attribute the observed changes in NLCs. ${ }_{37}$ Thus, at present, a complete picture of the possible impact of climate change 38 on NLCs is only possible with the use of atmospheric models. A recent study 39 by Lübken et al. (2009) uses a high-horizontal-resolution global model that 40 is "nudged" to re-analysis data in the troposphere and lower stratosphere, in ${ }_{41}$ conjunction with a three-dimensional ice transport model. Since the concen42 trations of $\mathrm{CO}_{2}, \mathrm{CH}_{4}$ and $\mathrm{O}_{3}$ are held fixed in their model simulation, the 43 only manifestation of climate change is through the temperature, wind and 44 water vapour changes in the lower atmosphere that are inherent in the re45 analysis data over the 1961 to 2008 time period. For July at $69^{\circ} \mathrm{N}$ their model 46 simulates a cooling of roughly $2.5 \mathrm{~K}$ at NLC peak altitudes $(\sim 83 \mathrm{~km})$ over 47 the time period from 1961 to the mid 1990s, and corresponding changes in 48 NLC properties that agree well with observations. The cooling of the summer 49 mesopause region was attributed to "thermal shrinking" of the stratosphere. 50 Although the authors noted that "dynamical effects" also contributed to 
One way in which dynamical changes in the troposphere and stratosphere 75 vertical coupling mechanism has been further investigated in the context of 
77 on the large-scale winds and temperatures in the MLT region (Ren et al., 78 2008).

Thus, changes in stratospheric winds can potentially induce changes in 99 region. 
attention. As with any model result, it is important to determine whether the result of Smith et al. (2010) is robust in the sense that it is also reproduced by other models. In particular, the Smith et al. (2010) results could potentially be affected by the severely delayed vortex breakdown in WACCM (Butchart et al., 2011).

It is furthermore unclear whether resolved waves play a role in the mesospheric response to the ozone hole. Since changes in mesospheric GWD can significantly affect the amplitude of planetary waves, such as the quasi-two day wave, that are generated in the shear zones of the easterly summer jet (e.g. Norton and Thuburn, 1999), it is possible that the mesopause response to the changes in GWD could be offset by changes in planetary wave drag. (Here we use the term "planetary wave drag" as a synonym for the EliassenPalm flux divergence associated with planetary waves, even when the flux divergence is positive and represents wave generation by baroclinic instability.) A proper accounting of the effects of both GWD and planetary wave drag is therefore required in order to correctly attribute the causes of the mesospheric response to the ozone hole.

To investigate the possible impact of the Antarctic ozone hole on the mesosphere we examine simulations from the Canadian Middle Atmosphere Model (CMAM), a chemistry-climate model that extends into the lower thermosphere. The simulations, which include the effects of both climate change and ozone depletion (and recovery), extend from 1960 to 2100. Although the primary motivation for this study is to examine the impact of the Antarctic ozone hole on summer polar mesopause temperatures, we also investigate the vertical coupling in late spring, when Antarctic ozone loss is at its maximum. 
The paper is organised as follows. In Section 2 CMAM and the simulations used here are described. The results are presented in Section 3, starting with an analysis of the model response and ending with an examination of the relative roles of GWD and planetary wave drag in producing that response. We close in Section 4 with a summary of our results and a comparison to results from other models. We also discuss possible implications for NLCs.

\section{Canadian Middle Atmosphere Model}

\subsection{Model description}

The Canadian Middle Atmosphere Model is a chemistry-climate model (CCM) that incorporates the physical and chemical processes that are important in the middle atmosphere. It is based on the Canadian Centre for Climate Modelling and Analysis (CCCma) general circulation model, and so inherits all of the physical processes in the troposphere that are included in that model (Scinocca et al., 2008). In the horizontal direction CMAM employs a T32 resolution $\left(\sim 6^{\circ} \times 6^{\circ}\right)$. In the vertical direction a hybrid coordinate is used, with 71 levels from the Earth's surface up to a pressure level of $0.0006 \mathrm{hPa}(\sim 95 \mathrm{~km})$, and an effective altitude resolution in the middle atmosphere of about $3 \mathrm{~km}$.

Momentum deposition (or drag) by unresolved small-scale gravity waves is parametrised using the non-orographic (i.e. non-zero phase speeds) GWD parametrisation of Scinocca (2003) and the orographic (i.e., zero phase speed) GWD parametrisation of Scinocca and McFarlane (2000). The non-orographic gravity waves are launched near $100 \mathrm{hPa}$ using a horizontally isotropic momentum flux spectrum containing waves propagating in the four cardinal 


\subsection{Model simulations}

For this study an ensemble of three simulations carried out as part of the SPARC CCMVal activity phase 1 (CCMVal-1) is used. All plotted results show the average of the three simulations. These so-called REF2 simulations (Eyring et al., 2007) extend from 1960 to 2100 and include the effects of climate change (from transiently increasing long-lived GHG concentrations) and ozone depletion (from transiently varying concentrations of ozonedepleting substances, ODSs). Surface concentrations of the GHGs $\mathrm{CH}_{4}, \mathrm{~N}_{2} \mathrm{O}$ and $\mathrm{CO}_{2}$ follow the observations in the past and are prescribed according to the A1B (medium) scenario of the IPCC (Intergovernmental Panel on Climate Change) "Special report on emissions scenarios" in the future (IPCC, 2000). Similarly, concentrations of ODSs follow the observations in the past 
${ }_{183} 6 \mathrm{~h}$ intervals.

\section{Results}

Since the cooling of the middle atmosphere due to GHG increases is to a first approximation the same in both hemispheres, an effective way to illustrate the impact of the ozone hole on temperature without the impact of climate change is to examine the differences between the southern and northern hemispheres. Figure 1, which is purely motivational, shows time series of the inter-hemispheric differences in polar-cap temperature between the Antarctic in December and the Arctic in June for the period 1960 - 2099, i.e. Antarctic minus Arctic. While we cannot unequivocally attribute all of the features seen here to the Antarctic ozone hole, it is clear from the temporal variation that the ozone hole plays the dominant role. A clear signal of the Antarctic cooling from halogen-induced ozone loss is seen by the temporal changes in the inter-hemispheric temperature differences below about $50 \mathrm{hPa}$, which decrease (i.e. the Antarctic becomes even colder than the Arctic) rapidly from the mid-1970s to about 2000, followed by a period of 
roughly constant values during 2000 - 2030, and then slowly increase towards the end of the 21st century, as the ozone levels recover. Between $50 \mathrm{hPa}$ and $\sim 0.05 \mathrm{hPa}$ the differences exhibit the same temporal behaviour, but with the opposite sign. This reflects the increased dynamical warming of the Antarctic upper stratosphere induced by the delayed vortex breakdown, which allows planetary wave forcing to continue later in the season (Manzini et al., 2003; Stolarski et al., 2006). Around $200 \mathrm{hPa}$ the temperature differences exhibit a cooling trend from the mid-1970s to about 2000, but then little change after that, as the dynamical effects of climate change in the SH early summer tend to offset the effects of ozone recovery (McLandress and Shepherd, 2009).

What is less expected is that in the upper mesosphere, centred around $0.003 \mathrm{hPa}$, the inter-hemispheric temperature differences in Figure 1 exhibit a similar temporal structure as observed in the stratosphere. This simple diagnostic therefore suggests a connection between these two altitude regions, induced by the influence of the Antarctic ozone hole. Opposite to what was found by Smith et al. (2010) the figure suggests a mesospheric cooling in the Antarctic mesopause region in December. As in Figure 1 a connection between the temporal behaviour of the inter-hemispheric differences in the stratosphere and mesopause region is also observed when November and May or January and July are compared with each other (not shown).

It should be noted that the model simulations used here produce higher temperatures in the Arctic summer mesopause region than in its southern counterpart, which is opposite to what is expected for this time of the year from observations (e.g. Hervig and Siskind, 2006; Karlsson et al., 2007; Lübken and Berger, 2007). The mesopause temperatures are also higher than 
observed (not shown). However, since we are examining a physical mechanism that couples the Antarctic stratosphere and the mesosphere (and not for instance trying to simulate NLCs which are strongly temperature dependent), this model bias is unimportant. We therefore focus on changes in the physical quantities, not on their absolute values.

To further demonstrate the connection between the Antarctic ozone hole and the mesopause region, Figure 2 shows time series of zonal wind in the stratosphere averaged from $55^{\circ} \mathrm{S}-75^{\circ} \mathrm{S}$ (black) and temperature in the mesopause region averaged over the polar cap from $70^{\circ} \mathrm{S}-90^{\circ} \mathrm{S}$ (grey) in November (upper panel), December (middle panel) and January (lower panel) from 1975 to 1995 , the time period over which the ozone hole was developing. The rationale for using zonal wind in the stratosphere is that the parametrised gravity waves, which are hypothesised to couple the two regions of the atmosphere, are sensitive to changes in the zonal wind through critical level filtering. The zonal winds are averaged from $40 \mathrm{hPa}$ to $1 \mathrm{hPa}$ in November, from $80 \mathrm{hPa}$ to $7 \mathrm{hPa}$ in December, and from $100 \mathrm{hPa}$ to $20 \mathrm{hPa}$ in January. These altitude ranges are chosen because that is where the most pronounced changes in the stratospheric zonal winds are found (see Figure 4). The mesospheric temperature data are averaged over the altitude range between $0.007 \mathrm{hPa}-0.001 \mathrm{hPa}$ for all months. The correlation coefficients between the three pairs of time series (plotted in the lower left corners 245 of the panels), which are statistically significant at the $99 \%$ level, indicate 246 a moderate to high degree of correlation between the two altitude regions. 247 Interestingly, the correlation is positive in November, but negative in Decem${ }_{248}$ ber and January, indicating that the mesospheric response to the ozone hole 
in our simulations is different in late spring and in summer.

Guided by the above results, we therefore focus on the months of November and December separately, and examine differences between the "present" (1996-2010), during which the Antarctic ozone hole had reached its peak and stabilised, and the "past" (1960-1974), before the Antarctic ozone hole began to develop. All figures showing differences between these two time periods show the $95 \%$ statistical significance levels, computed from monthly means using the t-test assuming randomly distributed Gaussian residuals.

\subsection{Ozone changes}

Before analysing the mesopause response to the Antarctic ozone hole, it is instructive to first examine the southern polar-cap ozone changes, which are shown in Figure 3 as a function of month. The strong ozone depletion in the lower stratosphere during the austral spring is clearly visible, peaking in October near $40 \mathrm{hPa}$. The ozone reduction persists into the austral summer, while descending to lower levels. The ozone hole is followed by a distinct increase in ozone at higher stratospheric altitudes during the summer and autumn, peaking in January just above $30 \mathrm{hPa}$. This ozone increase in the middle stratosphere arises in response to the extended period of planetary wave driven downwelling as mentioned earlier (Manzini et al., 2003; Stolarski et al., 2006). Model simulations, like those from CMAM shown here, tend to overestimate the temporal extent of the ozone increase, which in the obser270 vations is no longer visible by the beginning of the austral autumn (Stolarski 271 et al., 2006). This likely reflects the fact that in most models, the breakdown 2 of the Antarctic vortex occurs too late compared to observations (Butchart et al., 2011). In the upper stratosphere there is also a significant reduction in 
ozone, which is due to gas-phase chemical ozone destruction driven by chlorine increase. However, the upper stratospheric ozone loss has a much weaker latitudinal dependence than the ozone loss associated with the ozone hole, and thus a much weaker effect (through thermal wind balance) on the zonal mean zonal wind. In the mesosphere up to about $0.01 \mathrm{hPa}$ there is a small but statistically significant ozone decrease due to increasing concentrations of $\mathrm{CH}_{4}$ and subsequent $\mathrm{H}_{2} \mathrm{O}$ increase.

\subsection{Zonal wind and temperature response}

The top panels of Figure 4 show the past temperature and the present-minuspast temperature changes as a function of month for the polar cap. The largest temperature changes are seen in the lower stratosphere in November. The model results show a maximum cooling at about $70 \mathrm{hPa}$ of more than $10 \mathrm{~K}$, which is comparable to reanalyses (Langematz, 2000). As with ozone, the temperature decrease continues well into austral summer. In conjunction with the dynamically induced ozone increase near $10 \mathrm{hPa}$ (see Figure 3), a temperature increase is also observed. This warming persists throughout November to March. The peak warming altitude decreases from $5 \mathrm{hPa}$ in November to about $30 \mathrm{hPa}$ in March. In the mesosphere the model simulation exhibits a statistically significant cooling throughout December to June. This is due to a combination of increased $\mathrm{CO}_{2}$ concentrations and ozone loss as seen in Figure 3. Because this cooling has only a weak latitude dependence, 295 it does not have a significant impact on the zonal mean zonal winds. The 296 summer mesopause region shows a maximum temperature decrease of $4 \mathrm{~K}$ in ${ }_{297}$ December, with a decrease of $2 \mathrm{~K}$ lasting well into the second half of January. The only temperature increase occurs in October and November in the upper 
mesosphere, displaying a warming of $1 \mathrm{~K}$ to $2 \mathrm{~K}$ from past to present.

As a consequence of the stratospheric temperature changes resulting from the ozone hole, the zonal wind averaged from $55^{\circ} \mathrm{S}$ to $75^{\circ} \mathrm{S}$ (lower panels of Figure 4) increases in strength, with maximum changes of nearly $20 \mathrm{~m} / \mathrm{s}$ near $10 \mathrm{hPa}$ in November. The strengthened westerlies lead to a delay in the breakdown of the polar vortex of several weeks (Waugh et al., 1999). In conjunction with the zonal wind changes in the stratosphere are also changes in the mesosphere. In October and November the wind changes are positive, delaying the transition from westerlies to easterlies. In December and January, however, they are negative, indicating a strengthening of the prevailing easterlies. As we will show later, these differences in the zonal wind response in the mesosphere have important implications for the resolved wave drag response.

\subsection{Vertical coupling mechanism}

We now turn to the vertical coupling mechanism, first discussing the spatial structure of the responses in zonal wind, parametrised and resolved wave drag (represented through the Eliassen-Palm flux divergence - EPFD), and residual vertical velocity $\left(w^{*}\right)$, which is the vertical component of the transformed Eulerian mean circulation defined in Andrews et al. (1987). Then we diagnose the contributions from the wave drag terms to the $w^{*}$ response. We consider the months of November and December separately, since, as discussed earlier, the mesospheric responses are different. 


\subsubsection{Late Spring}

Commencing with November (i.e. late spring), the top two panels of Figure 5 show the latitude-height structure of the zonal mean zonal wind for the past (left) and the corresponding differences between the present and past (right) at southern mid-to-high latitudes. Similar plots for GWD, EPFD, and $w^{*}$ are shown in Figures $6-8$.

The positive zonal wind changes in November (Figure 5, top right) are visible over a wide range of latitudes, with a maximum value of over $20 \mathrm{~m} / \mathrm{s}$ near $65^{\circ} \mathrm{S}$ and $10 \mathrm{hPa}$. These changes strengthen the climatological westerlies in the lower stratosphere and push the zero-wind line higher up within the stratosphere (cf. top two panels of Figure 5). The strengthened westerlies filter out a larger fraction of the eastward propagating gravity waves, resulting in increased westward (i.e. negative) GWD in the mesosphere, peaking at about $-10 \mathrm{~m} / \mathrm{s} /$ day at $0.01 \mathrm{hPa}$ and $65^{\circ} \mathrm{S}$ (Figure 6, top right). (Note the different vertical axis ranges in Figures 5 and 6.) This negative GWD anomaly will drive anomalous polar downwelling, which, through adiabatic compression, will result in anomalous polar warming, which is consistent with the decrease in upwelling of the order of $1 \mathrm{~mm} / \mathrm{s}$ in the mesosphere near $70^{\circ} \mathrm{S}$ (Figure 8, top right) - note that the strong increase in mesospheric upwelling right over the pole seen in this figure actually contributes very little to the polar cap average, which shows a net downwelling anomaly up to about $0.003 \mathrm{hPa}$ (see Figure 10) - and the increase in the polar-cap temperature in the upper mesosphere (Figure 4, top right). However, in addition to the changes in GWD, there are also changes in resolved wave drag, as seen in 45 the top right panel of Figure 7, which shows the EPFD. The mesospheric 
EPFD anomaly is generally weaker than the GWD anomaly and is of opposite sign. This will drive anomalous upwelling and cooling, thus partially offsetting the effects of GWD, which may explain why the decreases in $w^{*}$ near $75^{\circ} \mathrm{S}$ (Figure 8, top right) are weaker in the upper mesosphere.

To quantify the relative impacts of the parametrised and resolved wave drag on the $w^{*}$ changes, we perform a downward control analysis (Haynes et al., 1991), which enables us to compute the separate contributions to $w^{*}$ from different types of wave drag. Details of this analysis, in a similar context, can be found in Ren et al. (2008). The validity of the downward control analysis for this situation is assessed below. The top panels of Figure 9 shows latitude-height plots of the changes in $w^{*}$ for November computed using downward control. The left and right panels show the contributions from GWD and resolved wave drag, respectively. The contributions from these two terms have similar spatial structures, e.g. with GWD producing anomalous downwelling over the pole and resolved wave drag producing anomalous upwelling in that region, but are opposite in sign. However, since poleward of $\sim 50^{\circ} \mathrm{S}$ the magnitude of the $w^{*}$ contributions from GWD exceeds that from the resolved wave drag, the sum of the two (not shown) yields a spatial pattern more similar to the GWD term in that region.

Since we are interested in the changes in polar temperature induced by changes in $w^{*}$, the contributions from the two forcing terms computed using downward control, which are shown in Figure 9, should be averaged over the polar cap. These averages are shown in the top panel of Figure 10 for November, with the GWD contribution in blue, the resolved wave drag 70 contribution in red, and the $w^{*}$ changes (computed from the right panel of 
Figure 8) in black. The dashed green line shows the residual term, given by the difference between $w^{*}$ and the sum of the $w^{*}$ contributions from the two forcing terms. The fact that the residual term is much smaller than the other terms demonstrates that the downward control calculations are accurate, and can thus be used to attribute the $w^{*}$ changes. This figure clearly shows that the anomalous mesospheric downwelling is driven mainly by GWD, but is offset by about $50 \%$ by the effects of the anomalous upwelling from the resolved wave drag.

As noted earlier, the correlation between stratospheric zonal wind and mesospheric temperature over the polar cap is positive in late spring, but negative in summer (Figure 2), which is what prompted us to examine the responses in November and December separately. The remainder of this section therefore focuses on the results for early summer.

\subsubsection{Early Summer}

The bottom panels of Figure 5 show the zonal mean zonal wind for December, for the past and the differences. The impact of the Antarctic ozone hole on the winds exhibits different signs in the stratosphere and mesosphere. In the stratosphere positive changes can be observed, peaking at around $65^{\circ} \mathrm{S}$ at about $30 \mathrm{hPa}$. These anomalous westerly winds result in a vertical extension of the region of westerlies to about $10 \mathrm{hPa}$, causing an increase in westward GWD up to about $0.01 \mathrm{hPa}$ (Figure 6 , bottom right). In the mesosphere, changes in the zonal wind are negative, corresponding to stronger easterlies in this altitude region. The wind changes maximise close to $65^{\circ} \mathrm{S}$ at about $0.03 \mathrm{hPa}$. The stronger easterlies in the polar mesosphere also modify 5 the propagation conditions for gravity waves but in an opposite way to the 
stronger westerlies in the lower stratosphere, leading to an enhanced eastward GWD in the upper mesosphere. As in November, the changes in EPFD indicate an increase of eastward resolved wave drag (Figure 7, bottom right). However, unlike November, the EPFD increase in December is much more pronounced in the upper mesosphere and even stronger than the changes in GWD. The changes in $w^{*}$ shown in Figure 8 (bottom right) are substantially larger in magnitude than those in November, and exhibit a pronounced increase in upwelling in the polar mesopause region, in line with the temperature decrease that is visible in Figure 4 (top right). The peak increase in $w^{*}$ exceeds $6 \mathrm{~mm} / \mathrm{s}$ and occurs close to $80^{\circ} \mathrm{S}$ at about $0.004 \mathrm{hPa}$. The lower panels of Figure 9, which show the downward control contributions to $w^{*}$, clearly show that the overall change in $w^{*}$ in the upper mesosphere is dominated by the changes in the resolved wave drag, while in the lower and to some extent middle mesosphere, changes in GWD are of greater importance. The relative roles of the parametrised and resolved wave drag in driving the changes in $w^{*}$ over the polar cap are further highlighted in the bottom panel of Figure 10, which shows that the resolved wave drag is the dominant driver of the anomalous upwelling in the upper mesosphere.

\subsection{In-situ wave generation in the mesosphere}

The pronounced change in the resolved wave drag differences in the upper mesosphere between November and December is interesting and warrants further investigation. One possible explanation for this may be changes in in-situ wave generation in the mesosphere. To see whether changes in the stability properties of the zonal mean state could account for the observed change in resolved wave drag, we examine the latitudinal derivative of Er- 
tel's potential vorticity (PV). Regions where the PV gradient is negative are potentially baroclinically or barotropically unstable, and thus represent potential sources of wave activity. Figure 11 shows latitude-height plots of the zonal mean zonal wind (contour lines) and the corresponding regions of negative PV gradients (shading) for November and December for the past (left) and present (right). Comparing the top and bottom panels, we immediately see that it is in December where the greatest change in the negative PV gradients occurs, undergoing a sharp decrease from past to present in the polar upper mesosphere. This would explain the large increase in the resolved wave drag changes in December (Figure 7, bottom right). Changes in the vertical shear of the zonal mean wind appear to be largely responsible, indicating that it is an increase in baroclinicity that is causing the large positive EPFD anomaly.

Further understanding of the in-situ wave generation can be obtained by decomposing the resolved wave drag changes into different zonal wavenumber $(k)$ bands. The left panels of Figure 12 show such a calculation. Here, EPFD changes (present minus past) for November and December are shown for three different bands: all wavenumbers $(k=1-32)$, planetary waves ( $k=1-3)$, and $k>3$, which we shall refer to simply as "synoptic" waves. The results have been averaged from $50^{\circ} \mathrm{S}$ to $90^{\circ} \mathrm{S}$, since that is the region encompassing the relevant resolved wave drag changes seen in Figure 7. Clear differences are seen in the seasonality of the EPFD changes. In November, planetary waves dominate, while in December synoptic waves are most important. Note also how in December the EPFD changes (both planetary and 45 synoptic) are primarily confined to the mesosphere. This is consistent with 
strong in-situ wave generation in the mesosphere. Previous modelling studies (e.g. Norton and Thuburn, 1999) have shown that baroclinic instability of the summertime mesospheric easterlies generates the quasi-two-day wave, and that its amplitude is very sensitive to the strength of the easterlies. In our simulation, the two-day wave amplitude is too small (not shown) as a result of our non-orographic GWD parametrisation (see discussion section).

Nevertheless, baroclinic instability is generating waves in the mesosphere in our simulations, but more as a spectrum of zonal wavenumbers, rather than as a single dominant zonal wavenumber like the two-day wave.

The right panels of Figure 12 show the contributions to the changes in polar-cap residual vertical velocity for the three zonal wavenumber bands, computed using downward control. In both months, planetary and synoptic wave drag changes induce anomalous upwelling. In November the planetary wave drag changes dominate, while in December it is the synoptic waves that are more important, which is consistent with the EPFD changes shown in the left panels.

\section{Summary and Discussion}

In this study we use simulations from the Canadian Middle Atmosphere Model (CMAM) to examine the impacts of the Antarctic ozone hole on temperatures in the southern polar mesopause region in late spring and early summer. A set of transient simulations that include both ozone depletion (and recovery) and GHG increases is analysed. Specifically, we analyse the changes between the period 1960 - 1974 (the "past"), before the ozone hole 
began to form, and 1996 - 2010 (the "present"), when a deep ozone hole was present. We focus on a dynamical process that couples the mesopause region to the stratosphere, namely parametrised (vertically propagating) gravity waves and the changes they undergo as a result of background wind changes in the stratosphere due to the ozone hole. In that respect our study is similar to that of Smith et al. (2010), who also examined the impact of the ozone hole on the Antarctic summer mesopause region. However, unlike their study, we also examine the resolved wave drag response in the mesosphere. We furthermore consider the late spring and early summer months separately, and find significantly different mesospheric responses in those two seasons.

Several pieces of evidence suggesting a coupling between the Antarctic lower stratosphere and upper mesosphere are presented. First, the time evolution of the inter-hemispheric differences between polar-cap temperatures in the Antarctic in December and in the Arctic in June follows the development and recovery of the ozone hole not only in the lower stratosphere but also in the upper mesosphere, suggesting a strong connection between the lower stratosphere and the upper mesosphere. Second, the zonal wind in the Antarctic stratosphere shows a moderately strong and statistically significant correlation with temperature in the Antarctic upper mesosphere during the spring and summer months over the period during which the ozone hole developed. Moreover, the largest upper mesospheric temperature changes during the ozone hole period occur during the months of November and December, the same time of year when the stratospheric temperature changes due to ozone depletion are at their maximum.

Analysis of the model results reveals that the temperature anomalies in 
the Antarctic mesopause region from November to January are induced by changes in parametrised GWD, resulting from changes in the zonal wind in the stratosphere associated with the ozone hole. The cooling of the Antarctic lower stratosphere that is caused by the reduced ozone levels, through thermal wind balance, strengthens the lower stratospheric westerlies, thereby extending the duration of the southern polar vortex into early summer. 1 The strengthened lower stratospheric westerlies increase the filtering of the parametrised eastward propagating gravity waves, resulting in anomalous westward GWD in the region above. Overall, a decrease in net GWD is observed, which results in a weakening of the residual mean circulation with weaker polar upwelling and an associated anomalous polar warming. This November response is similar to that reported in Smith et al. (2010).

In December the enhanced westward GWD in the mesosphere strengthens the prevailing easterlies making the vertical coupling from the Antarctic ozone hole to the mesopause region more indirect. The stronger easterlies, which have larger and deeper regions of negative PV gradients, are more baroclinically unstable, resulting in more generation of resolved waves in the upper mesosphere. This in-situ wave generation produces a spectrum of zonal wavenumbers $(k)$, which peaks in the synoptic wavenumber range (i.e. $k>3$ ). The enhanced positive Eliassen-Palm flux divergence (EPFD) in December drives the stronger polar upwelling in the mesopause region and its associated temperature decrease.

As alluded to in the previous section, the use of the Scinocca (2003) nonorographic GWD parametrisation results in a too-small amplitude quasi-two day wave in the summer mesosphere. Simulations using the extended version 
of CMAM, which employs the Hines (1997a,b) GWD parametrisation, produce a more realistic two-day wave (McLandress et al., 2006). The reason for this, we believe, is due to the manner in which the gravity wave momentum flux is deposited in the two schemes, as is discussed in McLandress and Scinocca (2005). In the Scinocca scheme, waves tend to break lower down than they do in the Hines scheme. This results in a weaker zonal wind reversal in the summer upper mesosphere and correspondingly weaker vertical wind shears, which in turn would result in less unstable summer easterlies. This suggests that not only the GWD changes, but also the resolved wave

drag changes in the summer mesosphere induced by the ozone hole, will be sensitive to the particular non-orographic GWD parametrisation that is used.

Since the Hines scheme results in GWD being located higher up, it is possible that the impact of the ozone hole on changes in the in-situ generation of resolved waves in the mesosphere might even be larger than in our simulation using the Scinocca scheme. Further studies are needed to elucidate this possibility.

Because the negative PV gradient in December maximises around $0.002 \mathrm{hPa}$, it is certainly possible that the resolved wave drag response in the upper mesosphere is being affected by the location of the model lid at $0.0006 \mathrm{hPa}$. Further studies with a higher-lid model are needed to address this possibility. However, in December the effect of EPFD changes on polar downwelling exceeds that of GWD down to almost $0.03 \mathrm{hPa}$, well below the model lid, and in November their effect on $w^{*}$ maximises approximately at the same height. So we believe that the basic mechanism of anomalous mesospheric polar upwelling from EPFD changes induced by the ozone hole via GWD is robust, 

even though the quantitative details may depend on model specification including not only lid height but also non-orographic GWD scheme and the extent of the model bias in the timing of the breakdown of the stratospheric polar vortex (see below).

In January the Antarctic polar vortex is already broken down for some time (although there are still westerlies in the troposphere), but the changes that occur in the dynamical variables from past to present have rather similar structures as in December, just distinctly smaller. The changes in January might be in part interpreted as the decaying signal from the changes in December, however there might also be a contribution that arises from a direct coupling from the troposphere to the mesopause region (Siskind et al., 2003).

The WACCM results presented in Smith et al. (2010) indicate a warming in the mesosphere over November and December in response to the ozone hole, in contrast to our results which only show a warming in November. The structure of the changes that occur in the dynamical variables looks very similar in CMAM and WACCM, yet their absolute sizes differ significantly. All changes are larger in the WACCM simulation, after taking into account the fact that the changes in the WACCM study are calculated for a longer time period. Smith et al. (2010) note that their stratospheric temperature trends are too large compared to observations, a fact that has relevance for the changes in the other dynamical variables and which might explain the large differences between the WACCM and CMAM simulations. In fact Figure 14 of Butchart et al. (2011) shows that the southern hemisphere mean final warming date for WACCM is more than a month later than observed, mak- 
ng it an outlier in the $12 \mathrm{CCMs}$ compared in that figure. (Most models have a delayed breakdown of the SH vortex, which is most likely a result of insufficient wave drag, perhaps orographic GWD as suggested by McLandress et al. (2011).) This bias almost certainly explains why the mesospheric warming in WACCM induced by the ozone hole extends into the early summer, unlike in CMAM. In the CMAM simulations the Antarctic vortex breaks down about 15 days too late, so that the transition observed from the mesospheric warming trend in November to the cooling trend in December may in reality occur somewhat earlier.

Up to $0.01 \mathrm{hPa}$ the CMAM results can also be compared to simulations using the middle atmosphere configuration of ECHAM (European Centre Hamburg Model) presented by Manzini et al. (2003). In that work, simulations with fixed boundary conditions for 1960 and 2000 were compared with each other to estimate the influence of ozone depletion and increasing GHGs on the middle atmosphere. In the lower and middle mesosphere at $80^{\circ} \mathrm{S}$ the ECHAM simulations show a decrease in upwelling during November, December and January. This is in line with the CMAM simulations and the absolute changes in the residual vertical velocity compare very favourably between the two models. Only in the upper part of the middle mesosphere in December and January do the CMAM simulations exhibit an increase in upwelling which is not present in the ECHAM results. In terms of temperature the ECHAM simulations exhibit an increase from 1960 to 2000 in November and December in the middle mesosphere, while in January a pronounced cooling is found. The CMAM results are consistent with the ECHAM simulations but not all changes are statistically significant. Clearly, further model 
studies are required in order to determine which aspects of the modelled mesospheric responses to the ozone hole are robust between models.

The temperature changes in the polar mesopause region from past to present simulated by CMAM amount to about $-4 \mathrm{~K}$ in December and $-2 \mathrm{~K}$ in January. Such changes are sufficient to influence NLCs in a significant way (e.g. Rapp and Thomas, 2006; Lübken et al., 2007, 2009), assuming the background temperatures are low enough to allow ice particle formation. Observations by SBUV show an increase in the seasonal averaged NLC albedo since the start of operations in 1979 that is quantitatively consistent with the temperature decrease in the CMAM simulations (DeLand et al., 2007). For the Arctic summer mesopause region the CMAM simulations exhibit a temperature decrease from past to present that is smaller than in the Antarctic and consistent with the results from Lübken et al. (2009) (not shown). Whether the temperature decrease at NLC heights from past to present has been stronger in the Antarctic summer compared to its Arctic counterpart remains speculation due to the lack of direct measurements. Indirect measurements, such as the NLC albedo observations by SBUV, do not provide support for this conclusion, as the albedo changes have been stronger in the Arctic (DeLand et al., 2007). In November the CMAM simulations indicate a temperature increase of $2 \mathrm{~K}$ from past to present in the upper mesosphere, which potentially can have caused a delay in the onset of the NLC season over time. Due to the delay in the vortex breakdown in the last decades, the timing of the Antarctic vortex breakdown plays, under present conditions, an important role for the onset of the NLC season in the southern hemisphere. The later the vortex breaks down the later the NLC season begins, and vice 
versa (Gumbel and Karlsson, 2011; Karlsson et al., 2011).

The Antarctic ozone hole is expected to recover by the end of the century

${ }_{643}$ Andrews, D.G., Holton, J.R., Leovy, C.B., 1987. Middle atmosphere dynam- 

ics. Academic Press, New York.

Beig, G., Keckhut, P., Lowe, R.P., Roble, R.G., Mlynczak, M.G., Scheer, J., Fomichev, V.I., Offermann, D., French, W.J.R., Shepherd, M.G., Semenov, A.I., Remsberg, E.E., She, C.Y., Lübken, F.J., Bremer, J., Clemesha, B.R., Stegman, J., Sigernes, F., Fadnavis, S., 2003. Review of mesospheric temperature trends. Reviews of Geophysics 41, 1015.

Butchart, N., Charlton-Perez, A.J., Cionni, I., Hardiman, S.C., Haynes, P.H., Krüger, K., Kushner, P.J., Newman, P.A., Osprey, S.M., Perlwitz, J., Sigmond, M., Wang, L., Akiyoshi, H., Austin, J., Bekki, S., Baumgaertner, A., Braesicke, P., Brühl, C., Chipperfield, M., Dameris, M., Dhomse, S., Eyring, V., Garcia, R., Garny, H., Jöckel, P., Lamarque, J.F., Marchand, M., Michou, M., Morgenstern, O., Nakamura, T., Pawson, S., Plummer, D., Pyle, J., Rozanov, E., Scinocca, J., Shepherd, T.G., Shibata, K., Smale, D., Teyssèdre, H., Tian, W., Waugh, D., Yamashita, Y., 2011. Multimodel climate and variability of the stratosphere. Journal of Geophysical Research 116, D05102.

de Grandpré, J., Beagley, S.R., Fomichev, V.I., Griffioen, E., McConnell, J.C., Medvedev, A.S., Shepherd, T.G., 2000. Ozone climatology using interactive chemistry: Results from the Canadian Middle Atmosphere Model. Journal of Geophysical Research 105, 26475 - 26492.

DeLand, M.T., Shettle, E.P., Thomas, G.E., Olivero, J.J., 2007. Latitudedependent long-term variations in polar mesospheric clouds from SBUV version 3 PMC data. Journal of Geophysical Research 112, D10315. 
Eyring, V., Butchart, N., Waugh, D.W., Akiyoshi, H., Austin, J., Bekki, S., Bodeker, G.E., Boville, B.A., Brühl, C., Chipperfield, M.P., Cordero, E., Dameris, M., Deushi, M., Fioletov, V.E., Frith, S.M., Garcia, R.R., Gettelman, A., Giorgetta, M.A., Grewe, V., Jourdain, L., Kinnison, D.E., Mancini, E., Manzini, E., Marchand, M., Marsh, D.R., Nagashima, T., Newman, P.A., Nielsen, J.E., Pawson, S., Pitari, G., Plummer, D.A., Rozanov, E., Schraner, M., Shepherd, T.G., Shibata, K., Stolarski, R.S., Struthers, H., Tian, W., Yoshiki, M., 2006. Assessment of temperature, trace species, and ozone in chemistry-climate model simulations of the recent past. Journal of Geophysical Research 111, D22308.

Eyring, V., Waugh, D.W., Bodeker, G.E., Cordero, E., Akiyoshi, H., Austin, J., Beagley, S.R., Boville, B.A., Braesicke, P., Brühl, C., Butchart, N., Chipperfield, M.P., Dameris, M., Deckert, R., Deushi, M., Frith, S.M., Garcia, R.R., Gettelman, A., Giorgetta, M.A., Kinnison, D.E., Mancini, E., Manzini, E., Marsh, D.R., Matthes, S., Nagashima, T., Newman, P.A., Nielsen, J.E., Pawson, S., Pitari, G., Plummer, D.A., Rozanov, E., Schraner, M., Scinocca, J.F., Semeniuk, K., Shepherd, T.G., Shibata, K., Steil, B., Stolarski, R.S., Tian, W., Yoshiki, M., 2007. Multimodel projections of stratospheric ozone in the 21st century. Journal of Geophysical Research 112, D16303.

Fomichev, V.I., Jonsson, A.I., de Grandpré, J., Beagley, S.R., McLandress, C., Semeniuk, K., Shepherd, T.G., 2007. Response of the middle atmosphere to $\mathrm{CO}_{2}$ doubling: Results from the Canadian Middle Atmosphere Model. Journal of Climate 20, 1121 - 1144. 
Gadsden, M., 2002. Statistics of the annual counts of nights on which NLC were seen. The British Astronomical Association 45. Auro Section, Papers given at the "Mesospheric Clouds 2002" meeting in Perth, Scotland, 19 22 August 2002.

Garcia, R.R., Marsh, D.R., Kinnison, D.E., Boville, B.A., Sassi, F., 2007. Simulation of secular trends in the middle atmosphere, 1950-2003. Journal of Geophysical Research 112, D09301.

Gumbel, J., Karlsson, B., 2011. Intra- and inter-hemispheric coupling effects on the polar summer mesosphere. Geophysical Research Letters 38, L14804.

Haynes, P.H., Marks, C.J., McIntyre, M.E., Shepherd, T.G., Shine, K.P., 1991. On the 'downward control' of extratropical diabatic circulations by eddy-induced mean zonal forces. Journal of Atmospheric Sciences 48, 651 -680 .

Hervig, M., Siskind, D., 2006. Decadal and inter-hemispheric variability in polar mesospheric clouds, water vapor, and temperature. Journal of Atmospheric and Solar-Terrestrial Physics 68, 30 - 41.

Hines, C.O., 1997a. Doppler-spread parameterization of gravity-wave momentum deposition in the middle atmosphere. Part 1: Basic formulation. Journal of Atmospheric and Solar-Terrestrial Physics 59, 371 - 386.

Hines, C.O., 1997b. Doppler-spread parameterization of gravity-wave momentum deposition in the middle atmosphere. Part 2: Broad and quasi 
monochromatic spectra, and implementation. Journal of Atmospheric and Solar-Terrestrial Physics 59, $387-400$.

Holton, J.R., 1983. The Influence of Gravity Wave Breaking on the General Circulation of the Middle Atmosphere. Journal of Atmospheric Sciences $40,2497-2507$.

IPCC, 2000. Special report on emissions scenarios. Cambridge University Press.

Karlsson, B., Körnich, H., Gumbel, J., 2007. Evidence for interhemispheric stratosphere-mesosphere coupling derived from noctilucent cloud properties. Geophysical Research Letters 34, L16806.

Karlsson, B., Randall, C.E., Shepherd, T.G., Harvey, V.L., Lumpe, J., Nielsen, K., Bailey, S.M., Hervig, M., Russell, J.M., 2011. On the seasonal onset of polar mesospheric clouds and the breakdown of the stratospheric polar vortex in the southern hemisphere. Journal of Geophysical Research, in press.

Klostermeyer, J., 2002. Noctilucent clouds getting brighter. Journal of Geophysical Research 107, 4195.

Langematz, U., 2000. An estimate of the impact of observed ozone losses on stratospheric temperature. Geophysical Research Letters 27, 2077 - 2080.

Langematz, U., Kunze, M., Krüger, K., Labitzke, K., Roff, G.L., 2003. Thermal and dynamical changes of the stratosphere since 1979 and their link to ozone and $\mathrm{CO}_{2}$ changes. Journal of Geophysical Research 108, 4027. 
Lübken, F., Berger, U., Baumgarten, G., 2009. Stratospheric and solar cycle effects on long-term variability of mesospheric ice clouds. Journal of Geophysical Research 114, D00I06.

Lübken, F., Rapp, M., Strelnikova, I., 2007. The sensitivity of mesospheric ice layers to atmospheric background temperatures and water vapor. Advances in Space Research 40, $794-801$.

Lübken, F.J., Berger, U., 2007. Interhemispheric comparison of mesospheric ice layers from the LIMA model. Journal of Atmospheric and SolarTerrestrial Physics 69, $2292-2308$.

Manzini, E., Steil, B., Brühl, C., Giorgetta, M.A., Krüger, K., 2003. A new interactive chemistry-climate model: 2 . Sensitivity of the middle atmosphere to ozone depletion and increase in greenhouse gases and implications for recent stratospheric cooling. Journal of Geophysical Research 108,4429 .

McLandress, C., Jonsson, A.I., Plummer, D.A., Reader, M.C., Scinocca, J.F., Shepherd, T.G., 2010. Separating the Dynamical Effects of Climate Change and Ozone Depletion. Part I: Southern Hemisphere Stratosphere. Journal of Climate 23, $5002-5020$.

McLandress, C., Scinocca, J.F., 2005. The GCM response to current parameterizations of nonorographic gravity wave drag. Journal of Atmospheric Sciences 62, $2394-2413$.

McLandress, C., Shepherd, T.G., 2009. Simulated anthropogenic changes in 
the Brewer-Dobson circulation, including its extension to high latitudes. Journal of Climate 22, 1516 - 1540.

McLandress, C., Shepherd, T.G., Polavarapu, S., Beagley, S.R., 2011. Is missing orographic gravity wave drag near $60^{\circ} \mathrm{S}$ the cause of the stratospheric zonal wind biases in chemistry-climate models? Journal of the Atmospheric Sciences, in press.

McLandress, C., Ward, W.E., Fomichev, V.I., Semeniuk, K., Beagley, S.R., McFarlane, N.A., Shepherd, T.G., 2006. Large-scale dynamics of the mesosphere and lower thermosphere: An analysis using the extended Canadian Middle Atmosphere Model. Journal of Geophysical Research 111, D17111.

Norton, W.A., Thuburn, J., 1999. Sensitivity of mesospheric mean flow, planetary waves, and tides to strength of gravity wave drag. Journal of Geophysical Research 104, 30897 - 30912.

Ramaswamy, V., Chanin, M., Angell, J., Barnett, J., Gaffen, D., Gelman, M., Keckhut, P., Koshelkov, Y., Labitzke, K., Lin, J., O’Neill, A., Nash, J., Randel, W., Rood, R., Shine, K., Shiotani, M., Swinbank, R., 2001. Stratospheric temperature trends: Observations and model simulations. Reviews of Geophysics 39, $71-122$.

Randel, W.J., Shine, K.P., Austin, J., Barnett, J., Claud, C., Gillett, N.P., Keckhut, P., Langematz, U., Lin, R., Long, C., Mears, C., Miller, A., Nash, J., Seidel, D.J., Thompson, D.W.J., Wu, F., Yoden, S., 2009. An update of observed stratospheric temperature trends. Journal of Geophysical Research 114, D02107. 
Randel, W.J., Wu, F., 1999. A stratospheric ozone trends data set for global modeling studies. Geophysical Research Letters 26, 3089 - 3092.

Rapp, M., Thomas, G.E., 2006. Modeling the microphysics of mesospheric ice particles: Assessment of current capabilities and basic sensitivities. Journal of Atmospheric and Solar-Terrestrial Physics 68, 715 - 744.

Ren, S., Polavarapu, S.M., Shepherd, T.G., 2008. Vertical propagation of information in a middle atmosphere data assimilation system by gravitywave drag feedbacks. Geophysical Research Letters 35, L06804.

Scinocca, J.F., 2003. An accurate spectral nonorographic gravity wave drag parameterization for general circulation models. Journal of Atmospheric Sciences 60, $667-682$.

Scinocca, J.F., McFarlane, N.A., 2000. The parametrization of drag induced by stratified flow over anisotropic orography. Quarterly Journal of the Royal Meteorological Society 126, 2353 - 2394.

Scinocca, J.F., McFarlane, N.A., Lazare, M., Li, J., Plummer, D., 2008. Technical Note: The CCCma third generation AGCM and its extension into the middle atmosphere. Atmospheric Chemistry \& Physics 8, 7055 7074 .

Siskind, D.E., Eckermann, S.D., McCormack, J.P., Alexander, M.J., Bacmeister, J.T., 2003. Hemispheric differences in the temperature of the summertime stratosphere and mesosphere. Journal of Geophysical Research 108, 4051. 
Smith, A.K., Garcia, R.R., Marsh, D.R., Kinnison, D.E., Richter, J.H., 2010. Simulations of the response of mesospheric circulation and temperature to the Antarctic ozone hole. Geophysical Research Letters 37, L22803.

SPARC CCMVal, 2010. SPARC report on the evaluation of chemistryclimate models. V. Eyring, T. G. Shepherd, D. W. Waugh (Eds.), SPARC Report No. 5, WCRP-132, WMO/TD-No. 1526, http://www.atmosp.physics.utoronto.ca/SPARC.

Stolarski, R.S., Douglass, A.R., Gupta, M., Newman, P.A., Pawson, S., Schoeberl, M.R., Nielsen, J.E., 2006. An ozone increase in the antarctic summer stratosphere: A dynamical response to the ozone hole. Geophysical Research Letters 33, L21805.

Thomas, G.E., Jensen, E.J., Olivero, J.J., Schroeder, W., Toon, O.B., 1989. Relation between increasing methane and the presence of ice clouds at the mesopause. Nature 338, $490-492$.

Thomas, G.E., Olivero, J.J., DeLand, M., Shettle, E.P., 2003. Comment on "Are noctilucent clouds truly a "Miner's Canary" for global change?". EOS Transactions 84, $352-353$.

von Zahn, U., 2003. Are noctilucent clouds truly a "Miner's Canary" for global change? EOS Transactions 84, 261 - 264.

Waugh, D.W., Eyring, V., 2008. Quantitative performance metrics for stratospheric-resolving chemistry-climate models. Atmospheric Chemistry \& Physics 8, $5699-5713$. 
${ }_{824}$ Waugh, D.W., Randel, W.J., Pawson, S., Newman, P.A., Nash, E.R., 1999. Persistence of the lower stratospheric polar vortices. Journal of Geophysical Research 104, $27191-27202$.

${ }_{827}$ Wickwar, V.B., Taylor, M.J., Herron, J.P., Martineau, B.A., 2002. Visual ${ }_{828}$ and lidar observations of noctilucent clouds above Logan, Utah, at $41.7^{\circ} \mathrm{N}$. 829 Journal of Geophysical Research 107, 4054.

830 Witt, G., Martin-Löf, J., Wilhelm, N., Smith, W.S., 1964. High latitude 831 summer mesospheric temperatures and winds with particular regard to 832 noctilucent clouds. Space Research V, 820 - 821.

WMO/UNEP, 2003. Scientific assessment of ozone depletion: 2002. Global Ozone Research and Monitoring Project, Geneva, Switzerland.

835 WMO/UNEP, 2011. Scientific assessment of ozone depletion: 2010. Global Ozone Research and Monitoring Project, Report 52, Geneva, Switzerland. 


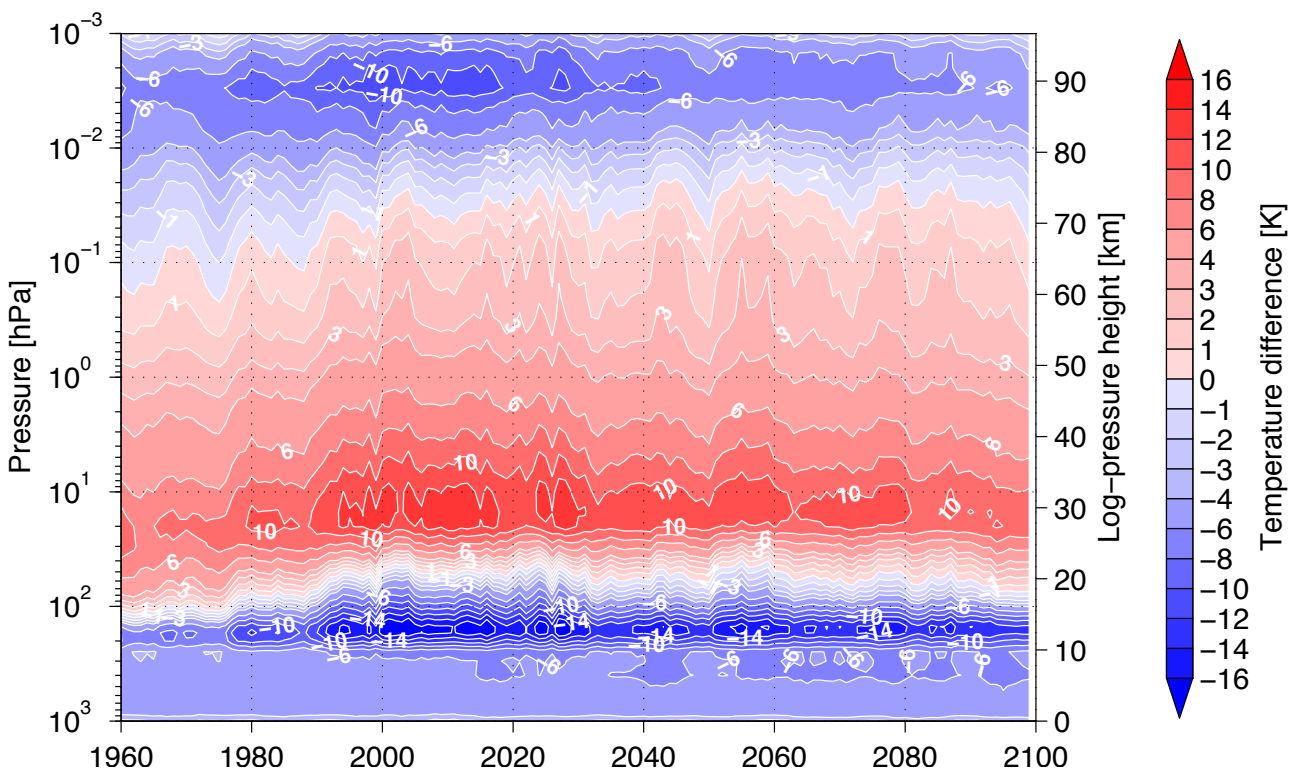

Figure 1: Inter-hemispheric differences in temperature between the Antarctic in December and the Arctic in June as function of year and pressure for the time period 1960 - 2099, i.e. Antarctic minus Arctic. The data are averaged between $70^{\circ}$ and $90^{\circ}$ in each hemisphere and smoothed with a 5-year running mean filter. The contour interval is $1 \mathrm{~K}$ for differences between $0 \mathrm{~K}$ and $\pm 4 \mathrm{~K}$ and $2 \mathrm{~K}$ for larger differences; negative values are blue, positive values are red. 

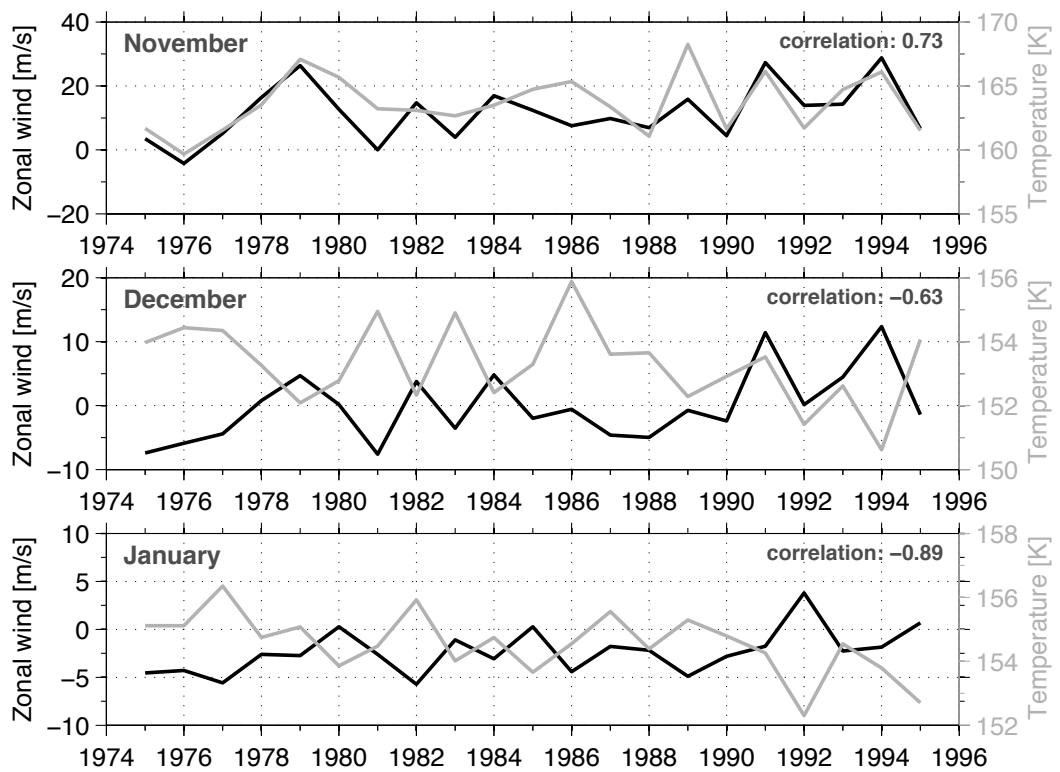

Figure 2: Time series of zonal mean zonal wind in the stratosphere (black) and temperature in the mesopause region (grey) for November (top), December (middle) and January (bottom) for the time period 1975 - 1995. The winds are averaged from $55^{\circ} \mathrm{S}$ to $75^{\circ} \mathrm{S}$, temperatures from $70^{\circ} \mathrm{S}$ to $90^{\circ} \mathrm{S}$. In the vertical, the winds are averaged from $40 \mathrm{hPa}$ to $1 \mathrm{hPa}$ in November, $80 \mathrm{hPa}$ to $7 \mathrm{hPa}$ in December, and $100 \mathrm{hPa}$ to $20 \mathrm{hPa}$ in January; these represent the altitude regions where the most pronounced zonal wind changes occur (see Figure 4). The temperatures are averaged in the vertical from $0.007 \mathrm{hPa}$ to $0.001 \mathrm{hPa}$ for all months. The correlation coefficients are plotted in the upper right corners; they are statistically significant at the $99 \%$ confidence level. 


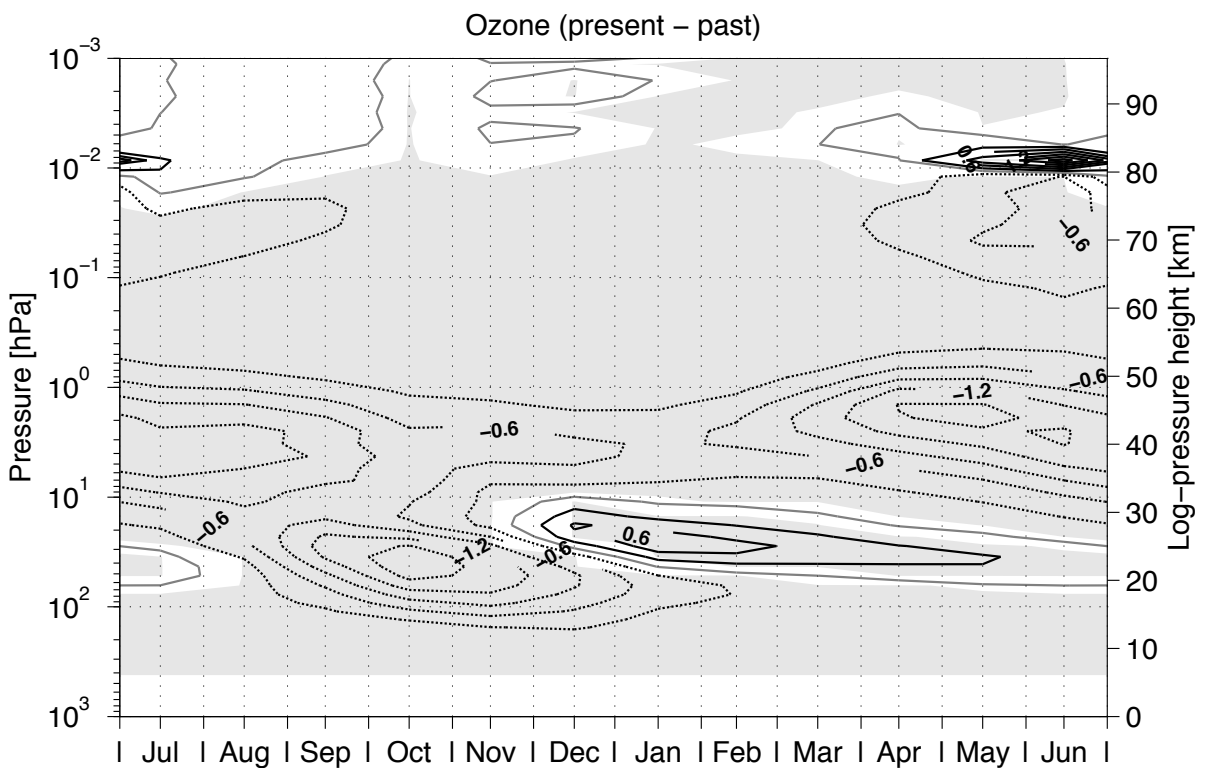

Figure 3: Differences in the polar-cap average $\left(70^{\circ} \mathrm{S}-90^{\circ} \mathrm{S}\right)$ ozone concentration between the present $(1996-2010)$ and past $(1960-1974)$ versus month and pressure. The data are monthly averages. The contour interval is $0.3 \mathrm{ppmv}$; negative values are dotted. The grey shaded areas indicate regions where the change exceeds the $95 \%$ significance level. 

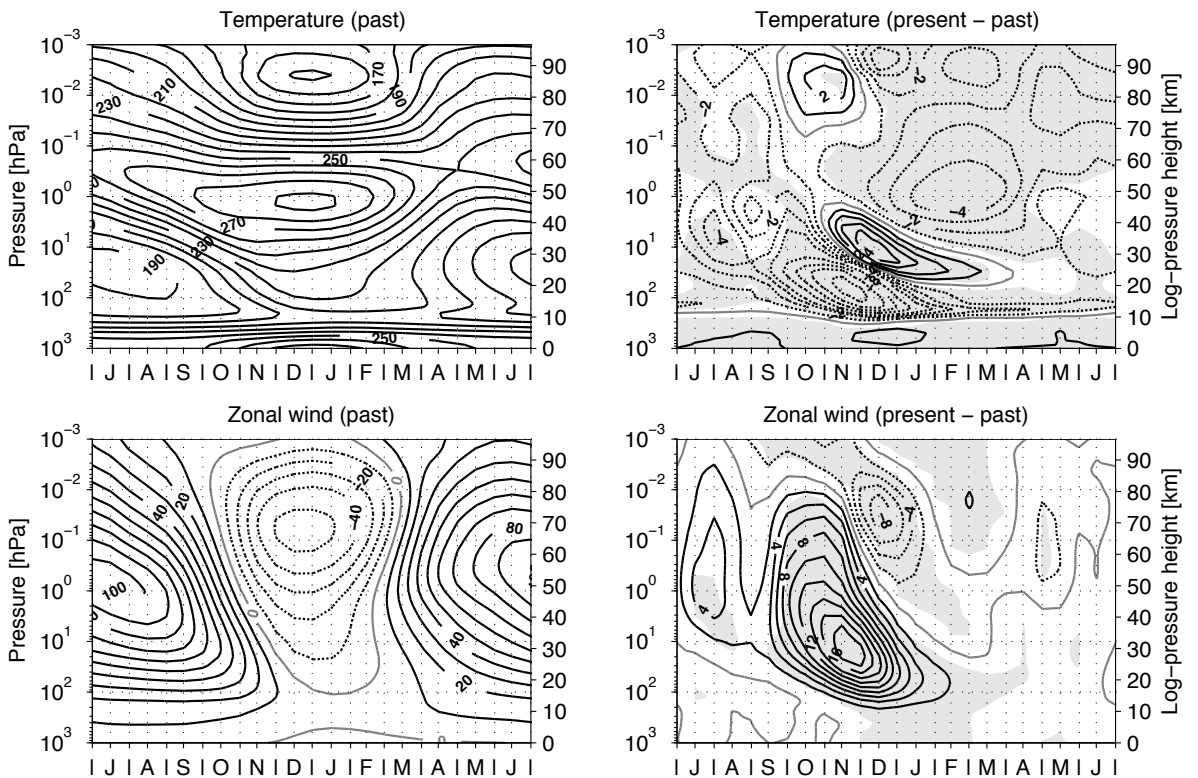

Figure 4: Polar-cap average $\left(70^{\circ} \mathrm{S}-90^{\circ} \mathrm{S}\right)$ temperature versus month and pressure for the past (top left) and the corresponding differences between the present and past (top right). Bottom row is the same but for the zonal wind averaged from $55^{\circ} \mathrm{S}-75^{\circ} \mathrm{S}$. The data are monthly averages. Contour intervals are $10 \mathrm{~K}$ and $10 \mathrm{~m} / \mathrm{s}$ for the temperature and zonal wind distribution in the past, respectively. The temperature changes use contour intervals of $1 \mathrm{~K}$ between $0 \mathrm{~K}$ and $\pm 4 \mathrm{~K}$ and $2 \mathrm{~K}$ for larger changes; for the zonal wind change the contour interval is $2 \mathrm{~m} / \mathrm{s}$. Negative values are dotted. The grey shaded areas indicate regions where the change exceeds the $95 \%$ significance level. 

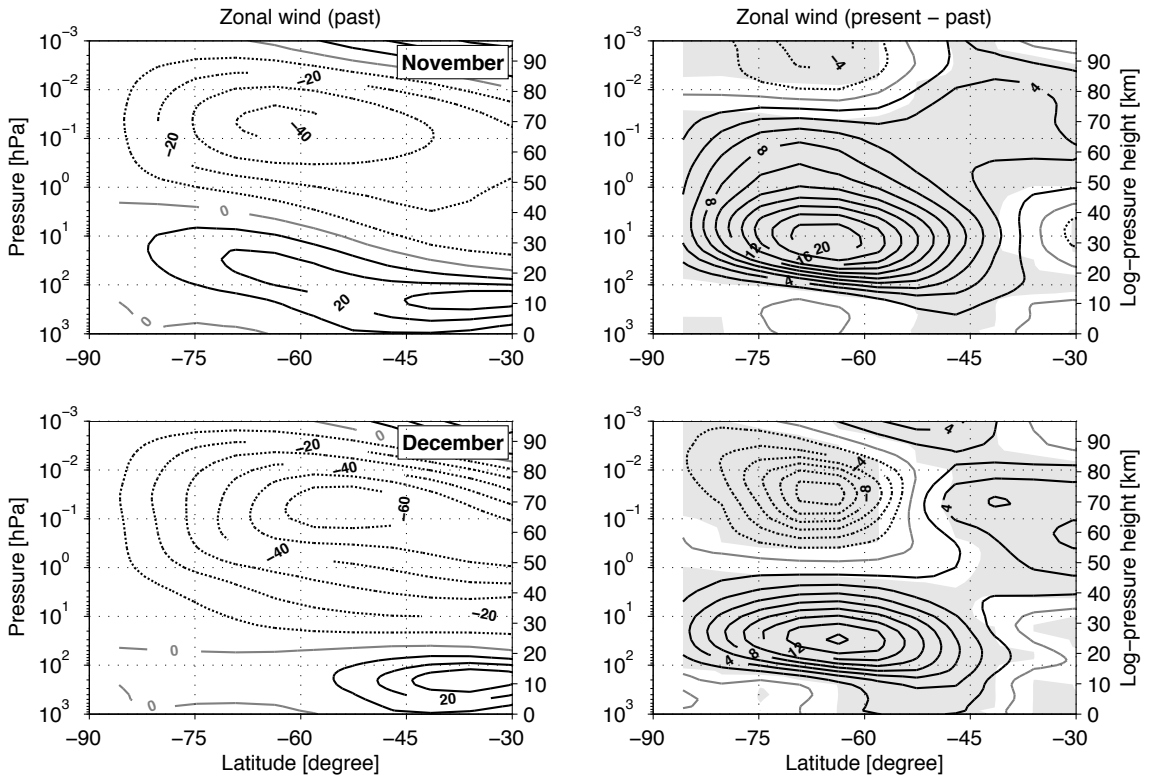

Figure 5: Zonal mean zonal wind for the past (left) and the corresponding differences between the present and past (right) for November (top) and December (bottom) as function of pressure and latitude from $30^{\circ} \mathrm{S}$ to $90^{\circ} \mathrm{S}$. Contour intervals are $10 \mathrm{~m} / \mathrm{s}$ (left) and $2 \mathrm{~m} / \mathrm{s}$ (right); negative values are dotted. The grey shaded areas indicate regions where the change exceeds the $95 \%$ significance level. 

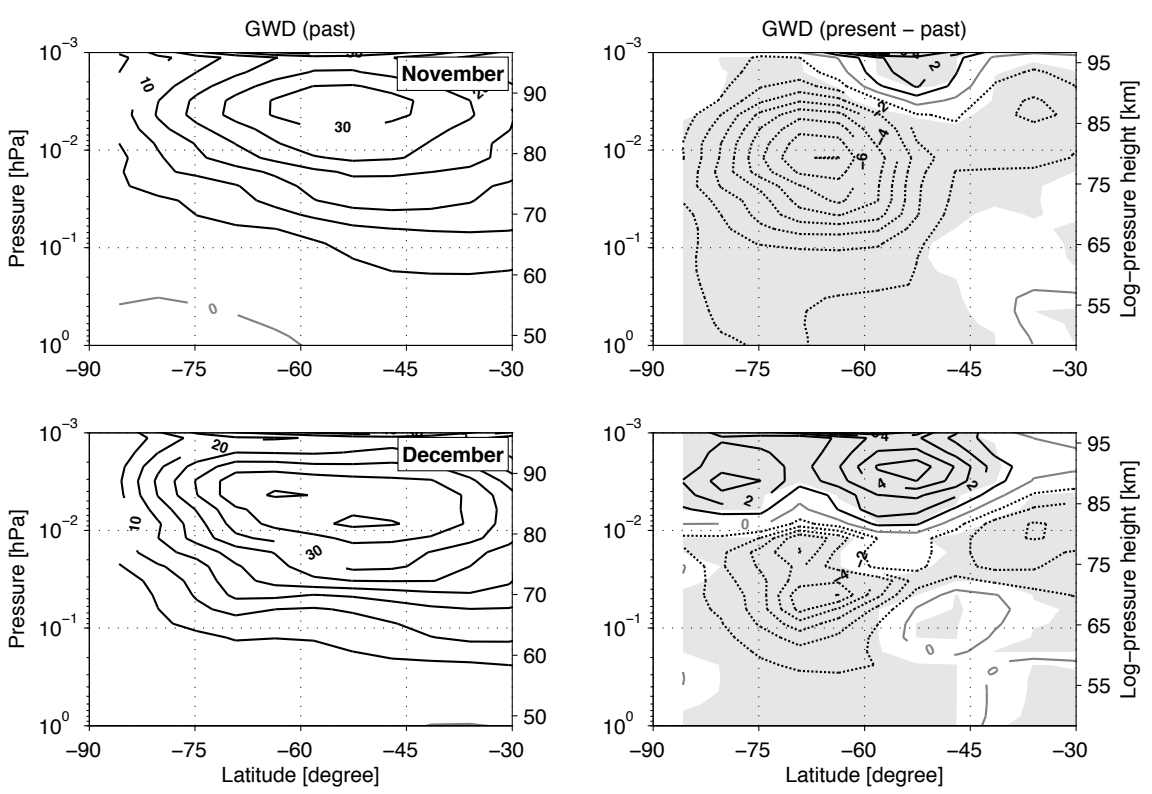

Figure 6: As in Figure 5 but for gravity wave drag. Contour intervals are $5 \mathrm{~m} / \mathrm{s} /$ day (left) and $1 \mathrm{~m} / \mathrm{s} /$ day (right). Note that the vertical axis range differs from that in Figure 5. 

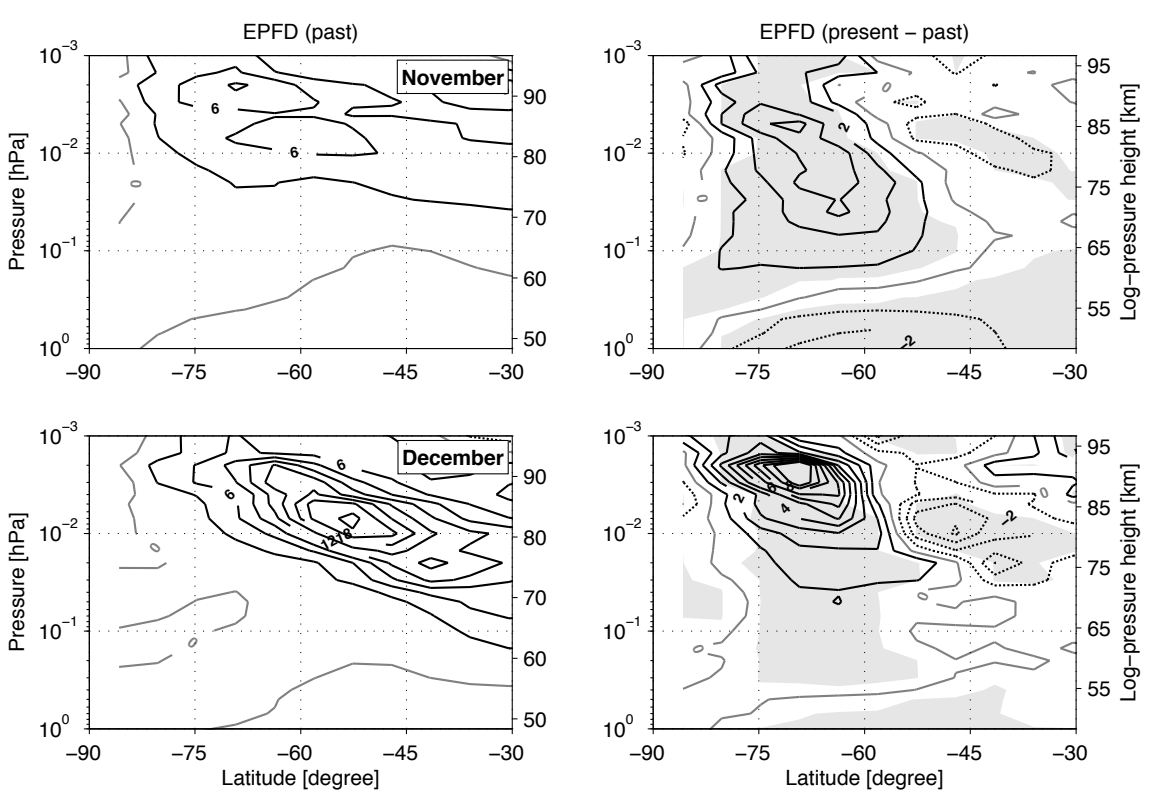

Figure 7: As in Figure 6 but for resolved wave drag (i.e. Eliassen-Palm flux divergence, expressed in units of force per unit mass). Contour intervals are $3 \mathrm{~m} / \mathrm{s} /$ day (left) and $1 \mathrm{~m} / \mathrm{s} /$ day (right). 

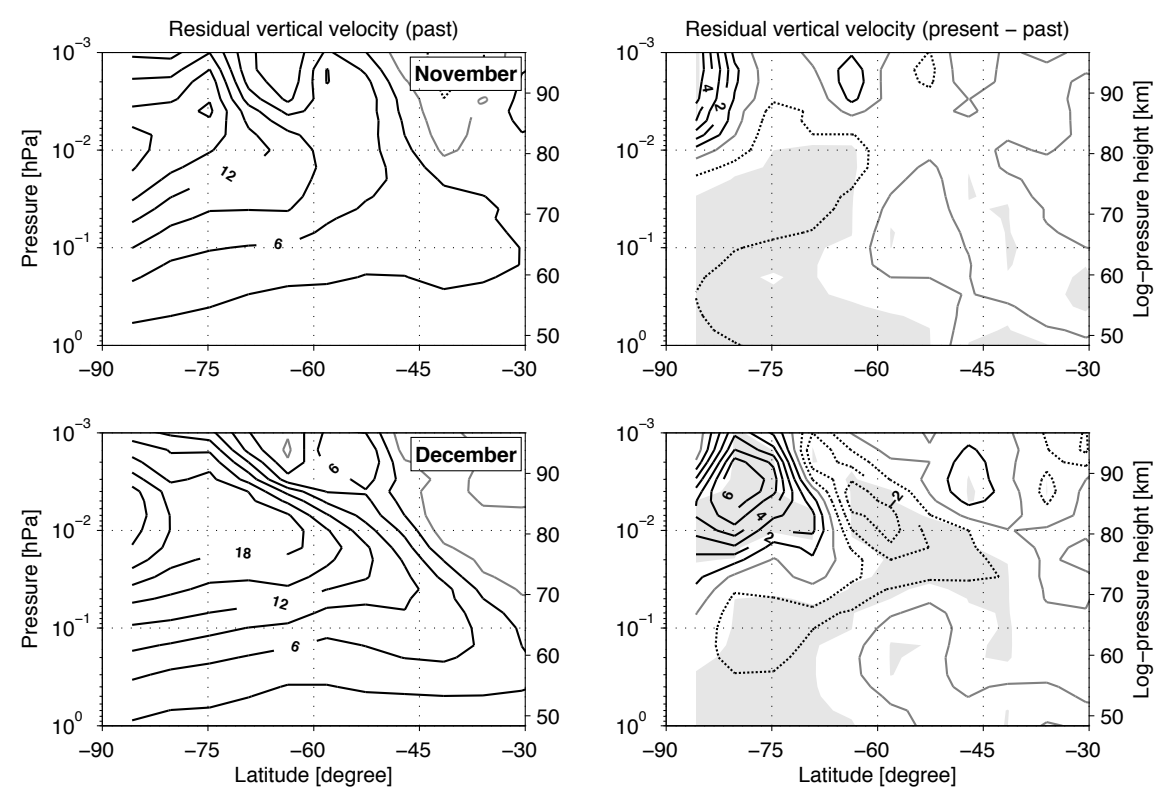

Figure 8: As in Figure 6 but for residual vertical velocity. Contour intervals are $3 \mathrm{~mm} / \mathrm{s}$ (left) and $1 \mathrm{~mm} / \mathrm{s}$ (right). 

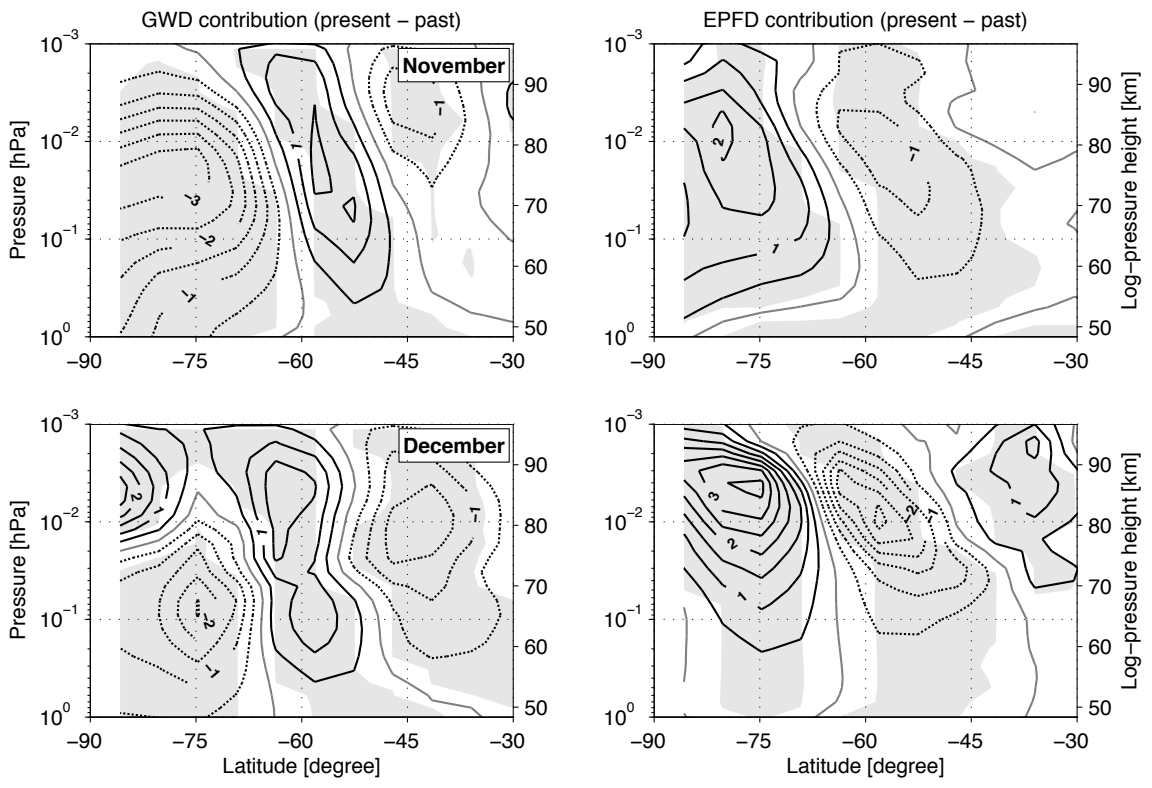

Figure 9: Downward control analysis showing the contributions of GWD (left) and resolved wave drag (EPFD, right) to the residual vertical velocity changes shown in the right panels of Figure 8 for November (top) and December (bottom) versus latitude and pressure. Contour interval is $0.5 \mathrm{~mm} / \mathrm{s}$; negative values are dotted. The grey shaded areas indicate regions where the change exceeds the $95 \%$ significance level. 

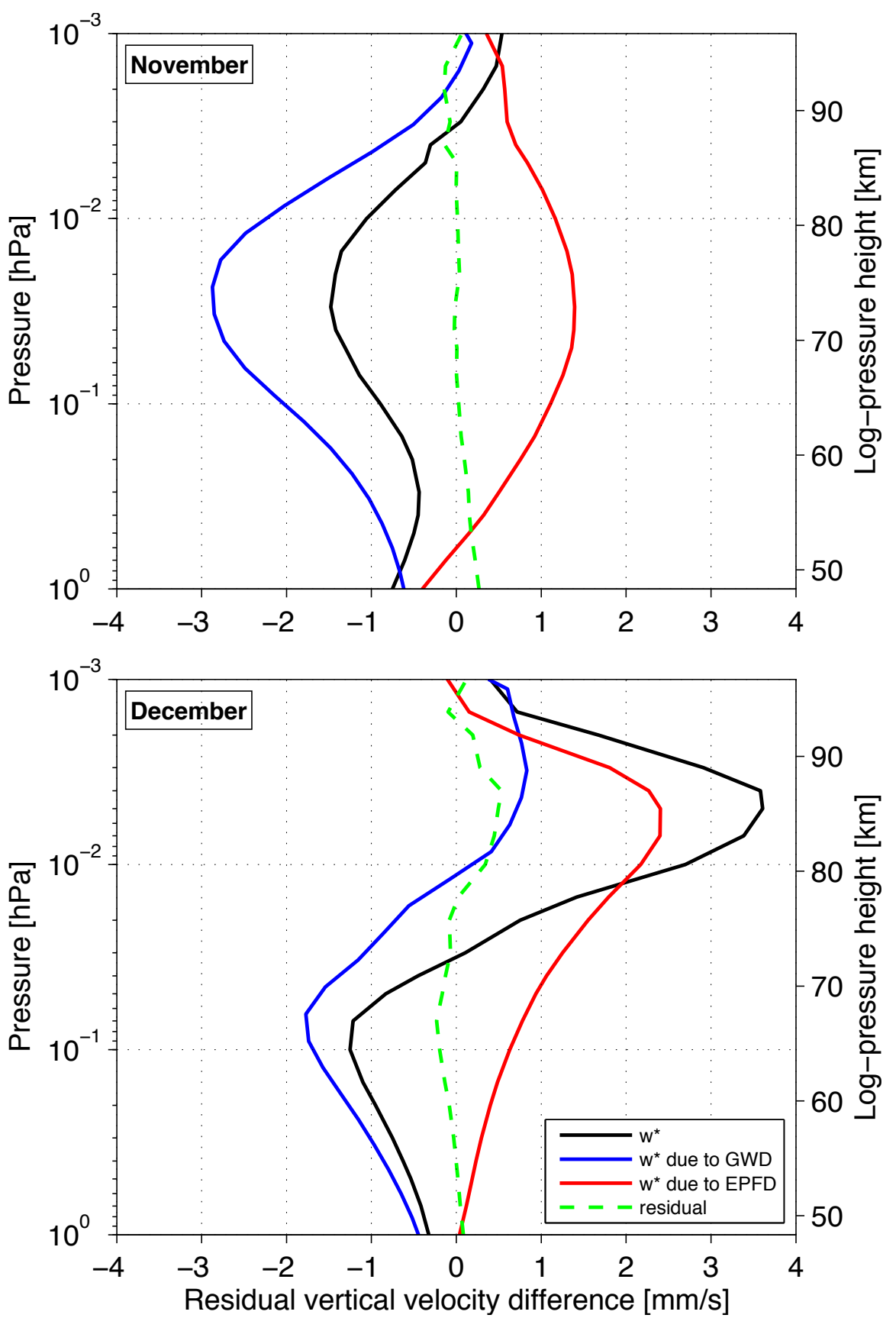

Figure 10: Downward control analysis showing vertical profiles of the contributions of GWD (blue) and resolved wave drag (EPFD, red) to the present-minus-past residual vertical velocity changes (black) for November (top) and December (bottom). The data are averaged from $70^{\circ} \mathrm{S}-90^{\circ} \mathrm{S}$. The green curve denotes the residual term, given by the difference between the residual vertical velocity $w^{*}$ changes (black) and those estimated from downward control (by summing up the blue and red curves). 

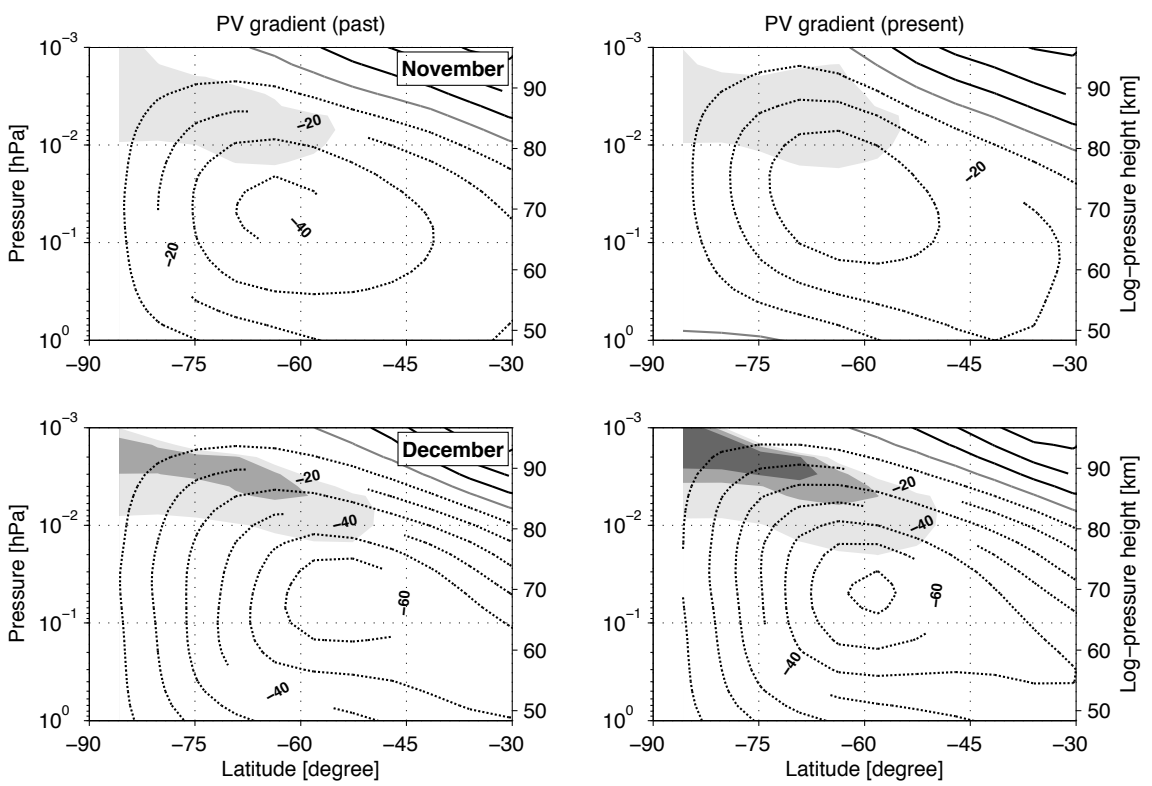

Figure 11: Latitudinal gradient of Ertel's potential vorticity (negative values only; shading) and zonal mean zonal wind (contours) for the past (left) and present (right) for November (top) and December (bottom). Shading levels are -0.1 to $-0.5 \cdot 10^{-7} \mathrm{~K} \mathrm{~m}^{2} \mathrm{~s}^{-1} \mathrm{~kg}^{-1}$ (light grey), -0.5 to $-0.9 \cdot 10^{-7} \mathrm{~K} \mathrm{~m}^{2} \mathrm{~s}^{-1} \mathrm{~kg}^{-1}$ (medium grey), and less than $-0.9 \cdot 10^{-7} \mathrm{~K} \mathrm{~m}^{2} \mathrm{~s}^{-1}$ $\mathrm{kg}^{-1}$ (dark grey). A contour interval of $10 \mathrm{~m} / \mathrm{s}$ is used for zonal wind; negative values are dotted. 

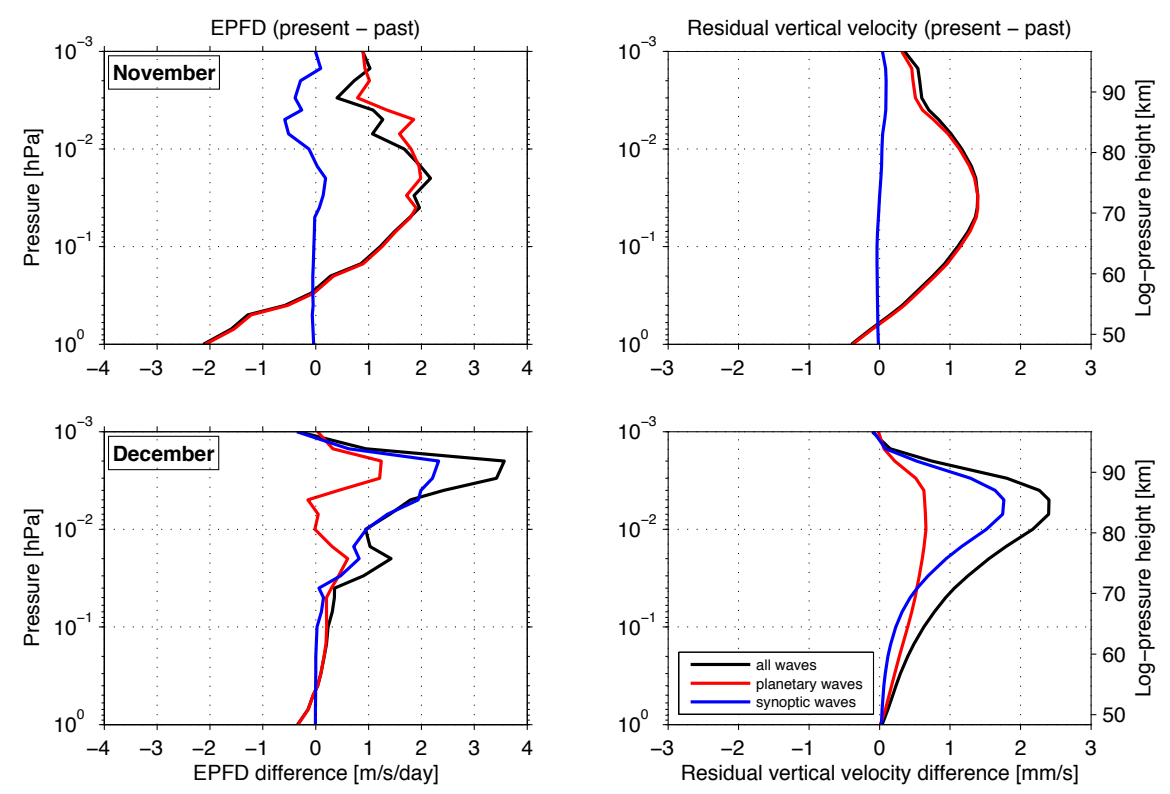

Figure 12: Left: EPFD differences (present-past) averaged from $55^{\circ} \mathrm{S}-75^{\circ} \mathrm{S}$ for three different zonal wavenumber bands (all waves, $k=1-32$; planetary waves, $k=1-3$; and synoptic waves, $k>3$ ) for November (top) and December (bottom). Right: Contributions of the different zonal wavenumber bands to the present-minus-past changes in the residual vertical velocity based on the downward control calculations, and averaged from $70^{\circ} \mathrm{S}$ $-90^{\circ} \mathrm{S}$. 